\title{
Cross-national studies on the teaching and learning of mathematics: where do we go from here?
}

\author{
Catherine P. Vistro-Yu
}

Accepted: 24 January 2013/Published online: 12 February 2013

(C) FIZ Karlsruhe 2013

\begin{abstract}
While the prevailing research interest in EastWest comparative studies still seems to be on explaining the superior performance of East Asian students, the time has come for researchers from both areas to focus on what countries can learn from one another. This commentary cites some of the most significant lessons learned from the papers in this special issue and asks additional research questions that might be worth pursuing. However, learning does not end in articulating similarities and differences between cultures and adopting the best practices that these cultures offer. It is hoped that countries will continue to work for increased partnerships and collaboration, greater understanding, and deeper appreciation of individual countries' uniqueness with the end goal of improving the quality of mathematics teaching and learning for all.
\end{abstract}

\section{Introduction}

\subsection{Why are East Asians so good in mathematics?}

This is the prevailing research question and, perhaps, the real question of interest behind cross-national, international, and East-West comparative studies that have dominated mathematics education research in recent decades. With East Asian countries topping each and every international achievement study that comes our way, the world remains perplexed, wondering how East Asians "do it". Other Asian countries are amazed as well, speculating with great interest and admiration whether they too could ever match the consistent, excellent performance of fellow

C. P. Vistro-Yu ( $\square)$

Ateneo de Manila University, Quezon City, Philippines

e-mail: cvistro-yu@ateneo.edu
Asians in Singapore, Japan, South Korea, Taiwan, Hong Kong and China.

Various explanations have been offered in an effort to unravel the mystery behind the mathematical superiority that East Asian countries continue to display. The most common explanation is simply "culture" (Clarke et al. 2006; Leung 2006; Ma 1999; Stevenson 1994). By "culture", these studies include beliefs, values, practices and language. Much has been said about the cultural dimensions of learning that seem to explain East Asian students' consistent, outstanding performance (Wong et al. 2009; Leung 2006; Li 2006). While Westerners might view these beliefs, values and practices as excessive (e.g. endless drills, yearly high stakes testing), those who have lived with and around East Asian students understand how and why these beliefs, values and practices work for them. Indeed, there is no magic formula for the East Asian students' success in mathematics. Hard work is at the core but, most especially, it is the deeper sense of purpose and meaning East Asian students attach to excellence that enables them to achieve (Lui and Leung, this issue).

On the other hand, shouldn't researchers focus on possible collaboration and examine the strengths and weaknesses of each nation's education system? The Japanese have their jukus (after-school centers), a long tradition of Lesson Study and a strong focus on problem solving in their mathematics lessons. The Singaporeans have an excellent mathematics curriculum, a workable mathematics framework and an enviable system of meritocracy. On the other hand, the Europeans have their didaktik (study of instruction), while the Americans have their strong research traditions in mathematics education. Surely, each country has its own strength and it would be a waste if we do not try to learn from one another. 


\section{Beyond international competition}

International comparative studies in mathematics can be a bane of the improvement of mathematics education in a country because many such studies have serious limitations. For one, international comparative studies are unable to show a complete picture of the mathematical phenomenon being studied. At best, they merely bare "in-themoment" realities that may not be typical and, therefore, are difficult to interpret or generalize. In their criticism of international studies, such as the Third International Mathematics and Science Studies (TIMSS 1995 and 1999), Keitel and Kilpatrick (1999) warn against what these purport to reveal or claim. They question curriculum and student achievement results, as well as constructs such as "performance expectations" and "perspectives" that fail to capture the complexities involved in the teaching and learning of mathematics in a particular country.

Other studies, such as cross-national comparative studies, may be more reliable. Cross-national studies offer important insights into different cultures, which are valuable lessons by themselves that researchers and educators in each nation should take to heart. For Cai and Lester (2007), crossnational studies provide opportunities to improve means of measuring student achievement and increase the chances for disseminating new ideas to improve the quality of mathematics learning in the classroom and in schools. In addition, perhaps, such studies can also allow for possible generalizability of results that try to explain high educational achievement (p. 270). The change of emphasis from competition to learning - that is, the shift from plotting individual country achievements through international survey studies, to identifying curricular contents, approaches and practices that countries may find worthy to adopt or emulate-is a welcome change. By focusing on aspects that countries have in common, or on contrasting features that make them different or even unique, and studying them over a longer period, researchers have a greater chance to reflect on parallelisms and disparities in order to understand more deeply the reasons for the gaps in mathematics achievement.

Countries learn more about their own educational practices and national values when they study other nations or cultures, but not when they merely measure themselves against other countries. Often, they fail to appreciate their scholarly strengths until they compare themselves with others, while at other times they may fall into complacency and be completely unaware that what they think is best is truly far from the ideal. Cross-national studies provide benchmarking opportunities for the countries involved (Blömeke and Delaney 2012; Nebres 1999) without threat of being ranked behind high-performing countries, and without the pressure of having to maintain a certain standard. This is because cross-national studies are meant to carry out genuine inquiry-based approaches with an openness to findings that may indeed delight or disappoint. Cross-national studies do not aim for countries to completely change their ways, giving up on what they value as a nation. This rings true particularly for East Asia and other Asian countries. Lim-Teo (2008) puts it succinctly: "what has worked well in the Confucian Heritage cultures will not work for the other cultures in Southeast Asia and each nation must work out what works best for them" (italics mine, p. 6).

Undoubtedly, cross-national studies make participating countries more vulnerable to the outside world, opening themselves up to scrutiny from both inside and outside their boundaries. But, this signals a willingness on the part of these countries to be exposed. This, for the most part, is admirable, and allows engagement in collaborative inquiry with the shared goal of learning more from others. For these studies to succeed, there must be a certain level of trust and understanding between and among researchers. Otherwise, the goal to learn will never be truly achieved.

The timing of this special issue on "Learning from Similarities and Differences: Cross-national Studies on Aspects of Teaching and Learning Mathematics" is perfect, because now is the time to focus more on learning, rather than on competition or ranking. The papers in this special issue offer rich ideas and insights in relation to mathematics curriculum, dialogue and discourse in the mathematics classroom, teaching and mathematics teachers' competence, from the perspectives of both East Asian and Western scholars. This commentary cites some of the most significant lessons learned from the papers and asks additional research questions that might be worth pursuing. Likewise, it challenges readers to look beyond the research and determine how these lessons might be appropriated in their own context with the desired goal to improve the teaching and learning of mathematics in schools.

\section{Lessons learned}

In the continuing search for excellence, and the improvement of the quality of mathematics teaching and learning, both Western and East Asian scholars seem to agree that comparative and cross-national studies presently offer the best route to achieve this goal. Styles and practices that are either similar or contrasting have become the subject of healthy debates and enlightening discussions. There is a lot to be learned from each other and, thus, a deeper look at some of these similarities and differences is well justified.

\subsection{Curriculum and opportunity-to-learn}

TIMSS 1995 showed that while participating countries offer a broad intersection of topics in their intended school 
mathematics curricula, significant differences were immediately apparent. International rankings clearly showed that not all countries teach the same mathematics, nor do they teach mathematics the same way. More importantly, the results of TIMSS 1995 emphasized that mere inclusion of content in the intended curriculum does not ensure the same levels of achievement across countries.

With regard to curriculum coverage, a common belief is that the earlier a concept is introduced, the better are the chances of students mastering the concept. We hear of high school teachers complaining about the delay in introducing the concept of variables, and other basic algebraic concepts, in primary school, for example. Yet, it is not only the timing of the introduction of certain concepts that is important. There are other factors to consider as well. In their secondary analysis of data from the International Project on Mathematical Attainment, Thompson et al. (this issue) called attention to the differences in the achievement of students from Japan, Singapore and the USA when compared with the grade at which the content is introduced. They found that while Singaporean students had more knowledge of numbers and basic arithmetic at the beginning of first grade, and thereby were in a better position to master the beginning content, by the end of fifth grade the same students were not much further ahead in achievement. In the same study, however, it was acknowledged that some concepts are introduced much earlier in Singapore while other concepts are introduced much earlier in Japan in contrast to the USA. A quick look at the mastery levels achieved by students from all three countries could easily lead one to conclude that timing is key to achieving mastery. However, a closer scrutiny will show that this is not true, as the US students' achievement scores indicated.

The fact that students from Singapore had higher achievement levels even before first grade clearly shows that there is something special about Singaporean students when they begin schooling. This perhaps deserves a deeper investigation, looking at the pre-school conditions, background and education at home of students from Singapore. What do Singaporean families and homes offer to their children that "gives them the edge" as soon as they enter first grade? What pre-existing conditions in the home or family contribute to Singaporean students' mathematical knowledge? How different are these from other East Asian homes? Singaporean parents put a premium on education and excellence (Wong et al. 2009). It would be interesting to research how they raise their children to do the same. Studies that focus more on the homes and family conditions of Singaporean students would be most interesting, if only to shed light on why and how Singaporeans, as early as first grade, show superior ability and potential for mastery of early number concepts in contrast to their counterparts in other countries.
One key idea in Thompson et al.'s (this issue) study that is worth revisiting is opportunity-to-learn (OTL). OTL is much more than merely the inclusion, or coverage, of desired content in the intended curriculum, as it was implicitly defined in the Second International Mathematics Study (Crosswhite et al. 1985). In a study of sixth grade students in Lima, Peru, by Cueto et al. (2006), OTL referred to curriculum coverage, cognitive demand of the tasks, and quality of feedback (p. 25). Walshaw (2012) described it similarly: OTL includes authentic applications from real life contexts, multiple representations, purposeful tasks, scaffolding by the teacher using meaningful tasks and visuals, explicit instruction, and also student exchanges and feedback (p. 425). It is the teacher who decides and designs the lessons and classroom activities, facilitates discussions and exchanges and develops assessment instruments for the students. Hence, ultimately, it is the teacher who determines the quality and quantity of opportunities students have in school to learn and understand mathematics meaningfully. OTL is not culture-free. The type of classroom setting and the selection of materials and classroom activities are all influenced by the teachers', students' or the school's culture, values and tradition.

On a deeper level, how teachers maximize students' opportunities to learn mathematics in the classroom is largely driven by their personal philosophies and beliefs, which may be heavily influenced by their country's culture and philosophy of education as well as the beliefs propagated by the national government (Andrews and Sayers 2013; Vistro-Yu and Villena-Diaz 2009). This was evident in the study by Lui and Leung (this issue) on how mathematics teachers in Hong Kong and Berlin differ in the ways they teach mathematics, despite having similar national philosophies of education. OTL is all about meaningful student engagement and richness of classroom learning experiences. However, different cultures have different meanings of some common terms (Clarke, this issue), such as "engagement" and "rich" classroom experiences. This is particularly true in East Asia, where they seem to mean ample drills and practice, written exercises with plenty of problem solving modeled by the teacher, supported by clear and organized explanations (Ma 1999; Leung 2006). In contrast, teachers in Berlin spend most of their classroom time engaging students in exploratory activities (Lui and Leung, this issue), something that German students value substantially.

Is one tradition better than the other? Is exploratory teaching, modeled by German teachers, superior to directive teaching modeled by Hong Kong teachers? At the outset, it does appear that Hong Kong students are deprived of better learning experiences, since they depend too much on what teachers tell and show, and since they do less group work. Hong Kong students hardly engage in 
exploratory activities compared with their German counterparts. But this would only be true if Hong Kong teachers lack competence and are therefore limiting their students to procedural learning filled with "mindless", repetitive exercises. Leung (2006) and Ma (1999), however, showed that mathematics teachers from Hong Kong, Korea and China are in fact very competent and possess a deep understanding of the mathematical concepts and procedures that they teach.

On the other hand, would German students' learning of mathematics differ much if more directive teaching were used? Exploratory methods and directive teaching each has its own benefits and shortcomings, but each could genuinely increase students' opportunities in learning mathematics, depending on how each is practiced. It would be interesting to see how each group of students would be affected by such a change in teaching styles. Would German students thrive or deteriorate in a classroom that predominantly uses directive teaching? Would East Asian students find exploratory teaching efficient and useful to them? It would be very informative to have some research that would study these questions.

\subsection{Dialogue and discourse}

East Asian students are known not to talk much in the classroom unless spoken to by their teacher (Clarke, this issue; $\mathrm{Xu}$ and Clarke, this issue; Koizumi, this issue). However, they continue to outperform their international counterparts in mathematics tests. There is a lot of learning going on even in their silence. While Westerners believe that talking is closely associated with thinking, East Asians do not assume such a direct correlation (Kim 2002 as cited by $\mathrm{Xu}$ and Clarke, this issue). In fact, the common belief among Asians is that if you understand, there is no need to talk. Xu and Clarke (this issue) cite a study by Inagaki et al. (1998) that showed Japanese students who are generally silent but are as engaged as verbal learners. There are forms of being actively engaged in class other than speaking aloud (Inagaki et al. 1998 as cited by $\mathrm{Xu}$ and Clarke, this issue). Some students listen intently as they process what they hear, while others quietly work on written exercises. Both learning types are learning as much as their outspoken, verbal classmates.

Despite the stereotypes of silent East Asian students, it is not true that they remain silent throughout class. $\mathrm{Xu}$ and Clarke (this issue) report on a portion of the Learners Perspective Study, comparing some of the discursive practices of classrooms in Seoul, Shanghai and Tokyo. Not surprisingly, in all three cities, verbal exchanges between teacher and student, and also student-student exchanges, are mathematically rich though probably limited and few. In fact, there was a lot of emphasis in the use of exact mathematical terms during discussions, especially in Shanghai where students are expected to use mathematical concepts to justify their work. This is exactly what Walshaw and Anthony (2008) referred to as "particular pedagogical approaches, purposefully focused on developing a discourse culture that elicits clarification and produces consensus within the classroom community" (p. 522). In addition, high expectations of constant use of mathematical terms and concepts in formal exchanges and interactions in a mathematics classroom make mathematical discourses richer and more superior.

Admittedly though, teacher talk is the most dominant form of talk in many East Asian classrooms, something that reform-minded teachers might avoid. Chorused responses by students are also very common in these classrooms, something perhaps that students in Western cultures rarely do. One might think then that all East Asian classrooms look and sound the same, but $\mathrm{Xu}$ and Clarke (this issue) are quick to point out that there are differences in the degree and in the manner that dominant teacher talk and chorused responses are practiced. For example, students in Tokyo are given opportunities to individually formulate processes and operations on their own and contribute to classroom discussions. The difficulty with teachers dominating classroom discussions in mathematics is that if a teacher is not fully competent, she can do plenty of damage that will be difficult to correct at a later stage. With students depending too much on what their teachers tell them, students could be learning the wrong concepts or procedures. However, it is equally true that students engaged in predominantly student-driven activities require teacher confirmation or correction.

Discourse in mathematics allows students to communicate with fellow students. They can add to what their teachers teach them, or teach each other alternative processes and ways of thinking. Discourse is a means for both students and teachers to check how much they know and understand as they engage in meaningful conversations about mathematics. Fruitful conversations require time and expert guidance on the part of teachers. Moreover, East Asian teachers need to be comfortable about having their own knowledge and understanding challenged and scrutinized by their students, something perhaps unheard of in the traditional classrooms that most East Asian teachers grew up in. It is indeed a challenge for mathematics teachers in East Asia to open up their classes to more discourse and to allow for genuine exchange of ideas between teacher and students, and among all students.

\subsection{Teacher competence}

The success or failure of mathematical discourse in the classroom depends on the knowledge and competence of 
mathematics teachers. If not well planned, or efficiently handled, mathematical discourse wastes time and effort. Teachers need to prepare good starting points for dialogue and discussion. Thus they need to have good questions ready and know when to pose them. This is probably the most difficult part of discursive teaching. How many times have we observed mathematics teachers pose questions meant to elicit discussions, only to have them fall flat and end the verbal exchange prematurely because of a "bad" question? The kinds of questions asked can make or break a good discussion. Equally important is how teachers assess their students' responses to the questions (whether or not they are acceptable or suitable), and what these teachers are able to do with the responses. Teachers have to know what to make of the responses, whether they make sense and could be used in the discussion.

Koizumi (this issue) studied the similarities and differences in the questioning techniques of mathematics teachers from Germany and Japan, deemed competent in their own countries. The introductory stage of a lesson and the way they value and assess students' responses were considered. The teachers from both countries were able to develop the lesson by incorporating students' responses to teacher questions, even though these questions were recall questions, or asked for mere recitation of procedures or calculations. However, upon a deeper analysis, particularly looking closely at the context within which these questions and responses were given, significant differences between the two countries were seen. The German teachers repeatedly asked questions in order to help students develop a way of thinking about the lesson. The Japanese teachers, on the other hand, intended for students to find mathematical meanings and relationships inherent in the lesson, and thus paid attention to individual students' responses to the questions. The difference is apparently due to culture. To the Japanese, the purpose of a question is to seek information. For the Germans, the answer to the question is not as important as the thinking process that a student goes through in order to produce the answer. In either case, teachers need deep mathematical content knowledge and pedagogical content knowledge to be able to follow through students' responses and to know exactly what to do with the responses.

The ability to ask good questions is just one of many skills expected of competent, expert mathematics teachers. There are many other skills required. With the kind of mathematical knowledge and understanding that students need to have, mathematics teachers are expected to know and do a lot more. For example, in a pilot study that compares prospective teachers from South Korea and Hong Kong, Leung et al. (this issue) assert that prospective teachers need to develop the ability to deal with counterexamples, and to be able to use these to justify mathematical propositions as well as when they teach proofs. On the other hand, one gets a glimpse of other knowledge and abilities that are expected of mathematics teachers in Yang and Leung's study (this issue). They report that there are withinculture similarities and differences in the conception of expert mathematics teachers, and they speculate that the similarities could be attributed to the common roots that the cities Chongqing and Hong Kong share, while the differences could be due to the differing working cultures and policies in the cities. It is important to note that, in both cities, expertise is viewed as having strong mathematical content knowledge and problem-solving ability, knowledge of learners, curriculum and learning theories, as well as possession of traits such as "noble personality" for Chongqing teachers, and passion for teaching in Hong Kong.

Certainly for East Asian countries, teachers' knowledge of mathematics and teaching competence are highly valued. Ask any citizen of East Asia, and the answer will be the same: teachers need to know their mathematics to be able to teach it. This is consistent with the findings by Kaiser and Blömeke (this issue) and Buchholtz et al. (this issue). Both comparative studies showed that content knowledge is important to East Asian teachers. In particular, Buchholtz et al. (this issue) found that prospective Korean elementary teachers have a strong mathematical background, which can be attributed to the strong content focus in their schools. In Kaiser and Blömeke's study (this issue), content expertise is one of a unified and integrated set of knowledge and skills that are expected of East Asian mathematics teachers. Clearly, the dictum, "You cannot teach what you do not know" is a statement that East Asian mathematics teachers subscribe to and seriously follow. Thus, teaching competence actually began when the teachers were school students themselves and first developed a solid mathematical knowledge and deep understanding of mathematical concepts and procedures. It is somewhat like developing a "cycle of competence" which first begins by providing a strong mathematical foundation for all students, some of whom will become mathematics teachers who will, in turn, teach in schools. With proper education and training in the pre-service level, future teachers are now able to teach better and stronger mathematics in schools, again producing better-prepared future mathematics teachers. It appears that East Asian countries have successfully begun a cycle of competence in mathematics in their schools. This is perhaps the greatest strength that these countries have, and which other countries should consider emulating.

\section{The future: where do we go from here?}

The papers in this special issue demonstrate that crossnational studies are rich in lessons that other nations and cultures can learn and use. Whether between cultures (i.e. 
East-West), or within cultures (e.g. all-East Asian or allEuropean), comparison and cross-national studies will always provide new perspectives to old research questions that relate to culture. For example, Andrews and Sayers (this issue) challenge the view that culture influences mathematics teachers' professional practices. Instead, they suggest that it is the means of analysis in the comparative studies of mathematics teaching that influences the outcomes of the studies. They found that when data from mathematics teachers in Spain, England, Hungary and Flanders were analyzed by country, each team of teachers exhibited common characteristics associated with their nationality. However, when the same data were analyzed by clusters, and not by nationalities, a different set of characteristics emerged. In fact, the data-driven analysis showed that within-culture practices are not so unique. The following questions warrant future studies:

1. How similar or different are mathematics teachers within each country in their teaching practices and beliefs about teaching competence and expertise?

2. How unique are the mathematics teaching practices of East Asian teachers? What other nationalities exhibit these?

3. What factors other than culture might explain similar teaching practices and views among East Asian students?

The lessons learned from cross-national comparative studies could transform countries in important ways. First, knowing that your country has some things in common with other countries is comforting. The inevitable next step is for researchers and educators from these countries to come together and forge a bond in the understanding that members continue to share new knowledge and discoveries whenever possible. This would generate long-term exchanges and partnerships that might even go beyond the fields of education and research, well into the social or political arenas. Second, realizing the contrasting views, beliefs, methods or philosophies between countries compels subsequent assessment of future directions. Relationships between countries could then go in either of two directions: (1) a temporary parting of ways, to allow for closer ties to emerge between countries that are similar; or (2) a tentative collaboration to learn the best practices available and to work together in experimenting with these practices in the hope that their views, beliefs, methods or philosophies might converge in the future.

The true purpose of cross-national studies is to learn from one another. Learning means first accepting one's faults and limitations, and then opening oneself to better ideas and methods. Learning also means acknowledging others' strengths and weaknesses, and choosing then what is best to accept and follow or to discard and avoid. However, learning does not end in articulating similarities and differences between cultures and adopting the best practices that these cultures offer. It goes on, and on, with the added goal of achieving cooperation and unity to improve the teaching and learning of mathematics in every school.

Increased collaboration and partnership, greater understanding of the complexities involved in the teaching and learning of mathematics, and deeper appreciation of a country's uniqueness and individuality-these are the hopes for a better, excellent quality of mathematics education for all.

\section{References}

Andrews, P., \& Sayers, J. (2013). Comparative studies of mathematics teaching: does the means of analysis determine the outcome? ZDM-The International Journal on Mathematics Education, 45(1). doi:10.1007/s11858-012-0481-3.

Blömeke, S., \& Delaney, S. (2012). Assessment of teacher knowledge across countries: A review of the state of research. ZDM-The International Journal on Mathematics Education, 44(3), 223-247.

Buchholtz, N., Leung, F. S. K., Ding, L., Kaiser, G., Park, K., \& Schwarz, B. (2013). Future mathematics teachers' professional knowledge of elementary mathematics from an advanced standpoint. ZDM-The International Journal on Mathematics Education, 45(1). doi:10.1007/s11858-012-0462-6.

Cai, J., \& Lester, F. (2007). Contributions from cross-national comparative studies to the internationalization of mathematics education: Studies of Chinese and U.S. classrooms. In B. Atweh, et al. (Eds.), Internationalisation and globalisation in mathematics and science education (pp. 269-283). Dordrecht: Springer.

Clarke, D. (2013). Contingent conceptions of accomplished practice: the cultural specificity of discourse in and about the mathematics classroom. ZDM-The International Journal on Mathematics Education, 45(1). doi:10.1007/s11858-012-0452-8.

Clarke, D., Kietel, C., \& Shimizu, Y. (Eds.). (2006). Mathematics classrooms in twelve countries: The insider's perspective. Rotterdam: Sense Publishers.

Crosswhite, F. J., Dossey, J. A., Swafford, J. O., McKnight, C. C., \& Cooney, T. J. (1985). Second international mathematics study summary report for the United States. Champaign, IL: Stipes.

Cueto, S., Ramirez, C., \& Leon, J. (2006). Opportunities to learn and achievement in mathematics in a sample of sixth grade students in Lima, Peru. Educational Studies in Mathematics, 62, 25-55.

Inagaki, K., Hatano, G., \& Morita, E. (1998). Construction of mathematical knowledge through whole-class discussion. Learning and Instruction, 8(6), 503-526.

Kaiser, G., \& Blömeke, S. (2013). Learning from the Eastern and the Western debate: the case of mathematics teacher education. ZDM-The International Journal on Mathematics Education, 45(1). doi:10.1007/s11858-013-0490-x.

Keitel, C., \& Kilpatrick, J. (1999). Rationality and irrationality of international comparative studies. In G. Kaiser, I. Huntley, \& E. Luna (Eds.), International comparative studies in mathematics education (pp. 241-257). London: Falmer Press.

Kim, H. S. (2002). We talk, therefore we think? A cultural analysis of the effect of talking on thinking. Journal of Personality and Social Psychology, 83(4), 828-842. 
Koizumi, Y. (2013). Similarities and differences in teachers' questioning in German and Japanese mathematics classrooms. ZDM-The International Journal on Mathematics Education, 45(1). doi:10.1007/s11858-012-0482-2.

Leung, F. K. S. (2006). Mathematics education in East Asia and the West: Does culture matter? In F. K. S. Leung, K. D. Graf, \& F. J. Lopez-Real (Eds.), Mathematics education in different cultural traditions - a comparative study of East Asia and the West: The 13th ICMI Study (Vol. 9, pp. 21-46). New York, NY: Springer.

Leung, I. K. C., Lew, H., \& Cheon, T. S. (2013). The ability of students and teachers to use counter-examples to justify mathematical propositions: A pilot in South Korea and Hongkong. ZDM-The International Journal on Mathematics Education, 45(1). doi:10.1007/s11858-012-0450-x.

Li, S. (2006). Practice makes perfect: A key belief in China. In F. K. S. Leung, K. D. Graf, \& F. J. Lopez-Real (Eds.), Mathematics education in different cultural traditions - a comparative study of East Asia and the West: The 13th ICMI Study (Vol. 9, pp. 129-138). New York, NY: Springer.

Lim-Teo, S. K. (2008). ICMI activities in East and Southeast Asia: Thirty years of academic discourse and deliberations. In M. Menghini, F. Furinghetti, L. Giacardi, \& F. Arzarello (Eds.), The first century of the International Commission on Mathematical Instruction (1908-2008) (pp. 247-252). Rome: Instituto della Enciclopedia Italiana.

Lui, K. W., \& Leung, F. S. K. (2013). Curriculum traditions in Berlin and Hong Kong - a comparative case study of implemented mathematics curriculum. ZDM-The International Journal on Mathematics Education, 45(1). doi:10.1007/s11858-012-0387-0.

Ma, L. (1999). Knowing and teaching elementary mathematics: Teachers' understanding of fundamental mathematics in China and the United States. Mahwah, NJ: Lawrence Erlbaum Associates.

Nebres, B. F. (1999). International benchmarking as a way to improve school mathematics achievement in the era of globalization. In
G. Kaiser, I. Huntley, \& E. Luna (Eds.), International comparative studies in mathematics education (pp. 200-212). London: Falmer Press.

Stevenson, H. (1994). Learning gap: Why our schools are failing and what we can learn from Japanese and Chinese education. New York, NY: Simon \& Schuster.

Thompson, D., Kaur, B., Koyama, M., \& Bleiler, S. (2013). A longitudinal view of mathematics achievement of primary students: Case studies from Japan, Singapore, and the United States. ZDM-The International Journal on Mathematics Education, 45(1). doi:10.1007/s11858-013-0485-7.

Vistro-Yu, C. P., \& Villena-Diaz, R. (2009). Teachers' beliefs, instructional practices, and culture: Understanding effective mathematics in the Philippines. In J. Cai, G. Kaiser, B. Perry, \& $\mathrm{N}$. Wong (Eds.), Effective mathematics teaching from teachers' perspectives: National and cross-national studies (pp. 183-202). Netherlands: Sense Publishers.

Walshaw, M. (2012). Opportunities to learn. Journal of Mathematics Teacher Education, 15, 425-427.

Walshaw, M., \& Anthony, G. (2008). The teacher's role in classroom discourse: A review of recent research into mathematics classrooms. Review of Educational Research, 78(3), 516-551.

Wong, K. Y., Lee, P. Y., Kaur, B., Foong, P. Y., \& Ng, S. F. (2009). Mathematics education: The Singapore journey (Vol. 2). Singapore: World Scientific Publishing.

$\mathrm{Xu}$, L., \& Clarke, D. (2013). Meta-rules of discursive practices in mathematics classrooms from Seoul, Shanghai and Tokyo. ZDM-The International Journal on Mathematics Education, 45(1). doi:10.1007/s11858-012-0442-x.

Yang, X., \& Leung, F. K. S. (2013). Conception of expert mathematics teacher: A comparative study between Hong Kong and Chongqing. ZDM-The International Journal on Mathematics Education, 45(1). doi:10.1007/s11858-013-0487-5. 